\title{
Effects of urban pollution on UV spectral irradiances
}

\author{
R. L. McKenzie ${ }^{1}$, C. Weinreis ${ }^{2}$, P. V. Johnston ${ }^{1}$, B. Liley $^{1}$, H. Shiona ${ }^{1}$, M. Kotkamp ${ }^{1}$, D. Smale ${ }^{1}$, N. Takegawa ${ }^{3}$, and \\ Y. Kondo ${ }^{3}$ \\ ${ }^{1}$ National Institute of Water and Atmospheric Research (NIWA), Lauder, PB 50061 Omakau, Central Otago, New Zealand \\ ${ }^{2}$ Institute of Meteorology and Climatology, Leibniz University of Hannover, Hannover, Germany \\ ${ }^{3}$ Research Center for Advanced Science and Technology, The University of Tokyo, 4-6-1 Komaba, Meguro, \\ Tokyo 153-8904, Japan
}

Received: 18 February 2008 - Published in Atmos. Chem. Phys. Discuss.: 14 April 2008

Revised: 14 August 2008 - Accepted: 27 August 2008 - Published: 29 September 2008

\begin{abstract}
Spectral measurements of UV irradiances at Tokyo are compared with corresponding measurements at a pristine site (Lauder New Zealand) to identify the causes of the reductions in urban UV irradiances, and to quantify their effects. Tropospheric extinctions in Tokyo were found to be up to $\sim 40 \%$ greater than at Lauder. Most of these differences can be explained by differences in cloud and aerosols, but ozone differences are also important in the summer. Examining spectral signatures of tropospheric transmission of both sites shows that reductions due to mean $\mathrm{NO}_{2}$ and $\mathrm{SO}_{2}$ amounts are generally small. However, at times the amount of $\mathrm{NO}_{2}$ can be 10 times higher than the mean amount, and on these days it can decrease the UVA irradiance up to $40 \%$. If $\mathrm{SO}_{2}$ shows comparable day to day variability, it would contribute to significant reductions in UVB irradiances. The results indicate that at Tokyo, interactions between the larger burden of tropospheric ozone and aerosols also have a significant effect. These results have important implications for our ability to accurately retrieve surface UV irradiances at polluted sites from satellites that use backscattered UV. Supplementary data characterising these boundary layer effects are probably needed.
\end{abstract}

\section{Introduction}

Previous studies have clearly demonstrated that UV irradiances at the surface are strongly influenced by tropospheric extinctions (Bais et al., 1993). These are thought to be significant contributors to the peak UV irradiances being approxi-

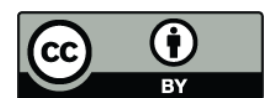

Correspondence to: R. L. McKenzie (r.mckenzie@niwa.co.nz) mately $40 \%$ higher in NZ than at corresponding latitudes in the Northern Hemisphere (McKenzie et al., 2006; Seckmeyer and McKenzie, 1992).

It is difficult to measure aerosol extinctions accurately in the UVB region. In the past it has been assumed that aerosol extinctions in the UVB region can be estimated by simple extrapolation from their effects in the visible and UVA regions. However, pollution effects may be much larger in the UV region than at other spectral regions. For example, many organic aerosols have absorption bands in this region, which would lead to reductions in UVB irradiance transmitted to the surface (Jacobson, 1998). In radiative transfer models, the effects of these aerosol extinctions may be modelled through reductions in their single scattering albedo.

An understanding of the causes of pollution effects is needed to improve estimates of geographical differences in $\mathrm{UV}$, which are usually derived from satellite-borne sensors that make use of solar UV radiation that is backscattered to the satellite sensor from the Earth's atmosphere. These satellite borne sensors include NASA's series of TOMS (Total Ozone Mapping Spectrometer), the SBUV instruments, and the more recent ozone monitoring instrument (OMI) on board the NASA EOS Aura satellite. Unfortunately, the mean backscattering altitude is located several kilometres above the Earth's surface, so assumptions must be made about the radiative transfer through the lower troposphere, including the boundary layer which can be polluted, especially over heavily populated areas. Consequently, these satellite sensors show a significant positive bias at polluted locations, including Tokyo (Tanskanen et al., 2005).

The present study attempts to quantify pollution effects by comparing spectral UV data from pristine and polluted locations. 
Table 1. Instrument specifications of the UV4 spectrometer system.

\begin{tabular}{ll}
\hline Parameter & Description \\
\hline Model & Acton, SpectraPro DSP-275 \\
Type & $\begin{array}{l}\text { Double Monochromator, Additive } \\
\text { Dispersion }\end{array}$ \\
Focal length (mm) & 275 \\
Focal ratio & $\mathrm{f} / 3.8$ \\
Grating type & Plane Holographic \\
Ruling $(/ \mathrm{mm})$ & 3600 \\
Dispersion $(\mathrm{nm} / \mathrm{mm})$ & 0.5 \\
Slit widths $(\mathrm{mm})$ & $1.0,1.5,1.0$ \\
Slit height $(\mathrm{mm})$ & 20 \\
Entrance optic & Shaped PTFE diffuser (in house design) \\
Coupling & Fibre Bundle $(1.95 \mathrm{~m} \times 20 \mathrm{~mm} \times 1.2 \mathrm{~mm}$ \\
& - GigaHertz) \\
Detector & Hamamatsu R1527 \\
Wavelength range & $285-450 \mathrm{~nm}$ \\
Resolution (fwhm) & $0.6 \mathrm{~nm}$ \\
Sample step & $0.2 \mathrm{~nm}$ \\
Normal Scan period & $272 \mathrm{~s}$ for forward + reverse scan \\
& $(3 \mathrm{speeds}$ are used in each scan, \\
& with slower scanning at shorter $\lambda$ ) \\
\hline
\end{tabular}

\section{Measurements}

This study makes use of data from a well-calibrated UV spectrometer system which was deployed at a pristine site: Lauder, New Zealand $\left(-45.04^{\circ} \mathrm{S}, 169.68^{\circ} \mathrm{E}\right.$, alt: $\left.370 \mathrm{~m}\right)$ and a polluted site: Tokyo, Japan $\left(35.66^{\circ} \mathrm{N}, 139.68^{\circ} \mathrm{E}\right.$, alt: $60 \mathrm{~m}$ ) for extended periods. The spectrometer system is the NIWA UV4 system which meets the demanding criteria set by the Network for the Detection of Atmospheric Composition Change (NDACC - formerly called the NDSC) (McKenzie et al., 1997; Wuttke et al., 2006). Instrument details are shown in Table 1. In normal operation the spectrometer is programmed to measure spectral irradiances over the wavelength range $285-450 \mathrm{~nm}$ at 5-degree steps in solar zenith angle (SZA) for SZA $\leq 95^{\circ}$, as well as at $15 \mathrm{~min}$ intervals for $2.5 \mathrm{~h}$ over the midday period. During the measurement period at Tokyo, the frequency of daylight scans was increased to once every $15 \mathrm{~min}$.

Calibrations are traceable to NIST, and the usual measurement uncertainty with these systems is better than $\pm 5 \%$. However, subsequent analysis of the data from Tokyo revealed a problem caused by a build-up of pollution on the surface of the unprotected PTFE diffuser, which was designed for use in less polluted places. The operators cleaned the diffuser at regular intervals, and before the stability calibration sequences, which were carried out at intervals of approximately two weeks. This regime was later found to be inadequate, and cleaning with water was generally carried out several times per week from early January 2005. Even with these additions, it was still necessary to back-correct data to take account of build-up of pollution on the diffusers. Fortunately, another NIWA spectrometer system with a domed entrance optic designed to measure actinic flux was operating alongside the spectrometer in question for most of the year. Over some periods of each day, the scans were simultaneous, and we were able to use data from that instrument to check and back-correct the measurements. This procedure is imperfect, since changes in aerosol properties can affect these two quantities differently. For example, at small SZAs, the presence of aerosols tends to increase the ratio of actinic flux to irradiance, whereas at larger SZAs it tends to decrease the ratio. However, these differences are relatively small at the SZAs that were used to deduce the correction, which was achieved by comparing irradiances and actinic fluxes measured at SZA $60-65^{\circ}$. The uncertainty from this effect was estimated from a sensitivity study using the tuv RT model, in which we calculated the effects of an increase in aerosol optical depth at $1 \mu \mathrm{m}$ from 0 to 0.235 . The contribution to the error budget is less than $4 \%$, and the increased error bars for the Tokyo data encompass any additional uncertainties from this source. Six periods were identified where increasing corrections were needed to account for this problem. The correction factors needed were independent of wavelength and were well approximated by a linearly increasing correction over these periods. The largest reductions in throughput were $\sim 20 \%$, and this correction procedure added an additional $5 \%$ to the overall calibration uncertainty. Over the summer periods (May through August) the diffuser was cleaned more regularly, and the maximum correction was $5 \%$.

Each scan logged is an average of a forward scan and a reverse scan, where the total scan time is approximately $5 \mathrm{~min}$. During the scan period, there can be significant changes in mean intensity due to changing cloud conditions. To recognise these occurrences, some of the radiation arriving at the entrance slit is intercepted by a diode detector which is sensitive to UVA radiation. At each wavelength sampled, this diode signal is also recorded.

A summary of irradiances and ozone amounts over these deployment periods is shown in Fig. 1. Ozone was from the NIWA ozone climate data base measurements (Bodeker et al., 2001), which is essentially satellite-derived ozone latitudinally re-normalised according to available ground-based ozone. The seasonal variabilities in UV irradiances are dominated by changes in SZA. The minimum SZAs at Lauder and Tokyo are approximately $22^{\circ}$ and $12^{\circ}$, respectively. Despite Tokyo's lower latitude (and smaller SZAs), the summertime irradiances measured there are less than at Lauder, especially during the second summer of operation. In the UVA region (integral $315-400 \mathrm{~nm}$, upper panel) the lower summertime values at Tokyo are attributable to the closer Sun-Earth separation in January compared with June (a 7\% effect), and to differences in cloud properties and tropospheric pollution, which will be discussed later. In contrast 

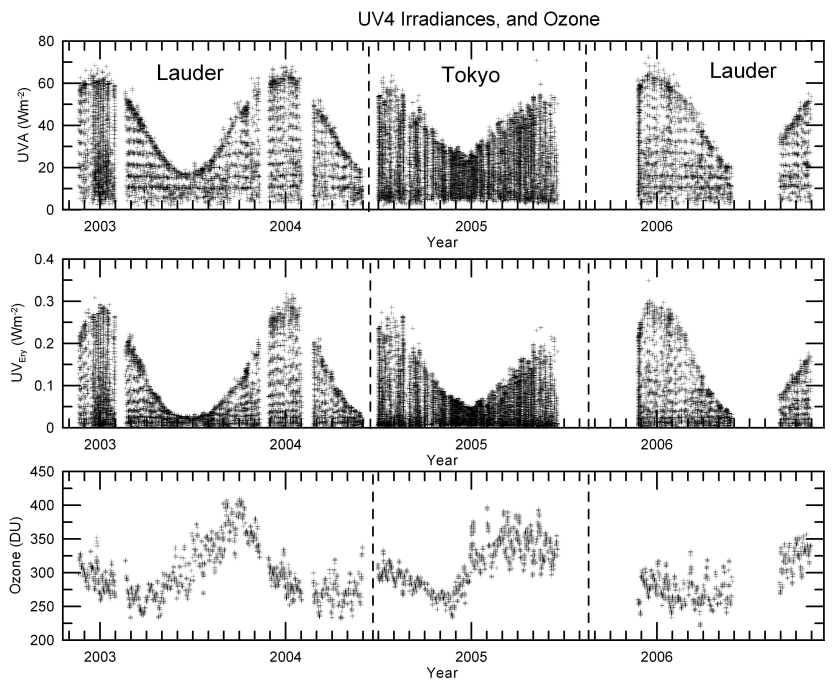

Fig. 1. History of UV4 deployment shown by time series of UV and derived ozone. The instrument was at Lauder from November 2002 to May 2004, and August 2005 to present. From June 2004 to June 2005 it was at Tokyo.

to the summer differences, winter irradiances are larger at Tokyo. This reversal is partly due to a reversal in the SunEarth separation effect, but the longer atmospheric paths at Lauder's higher latitude also become important, because of its larger SZAs in winter. These seasonal and geographic differences in UVA radiation are amplified in UVB radiation (280-315 nm), and therefore in erythemally-weighted irradiances (middle panel), which is more strongly scattered by air and aerosol, and is additionally absorbed by ozone. There are large day-to-day and seasonal variabilities in ozone, with maxima in spring, and minima in autumn. In summer, ozone columns are larger over Tokyo (lower panel), whereas in winter they are similar at both sites. The upper envelopes of these curves represent cloud-free conditions, although such conditions can be rare at Tokyo during the summer rainy season, which typically starts in mid-June. In addition to cloud effects, extinctions by aerosols can be large in Japan, and their seasonal variations in may be important. AERONET data from Japan (Chin et al., 2004) show an average optical depth of 0.3 to 0.5 at $550 \mathrm{~nm}$, with relatively small seasonal changes. However, this low seasonality contrasts with the situation in NE China, which is a source region for Japan, where even higher AODs have been reported, with a strong summer maximum that can exceed optical depth 1 at $500 \mathrm{~nm}$ (Wang et al., 2008).

A wide range of ancillary measurements are available at the Lauder NDACC site, including ozone and temperature profiles, and aerosol optical depth. It has been demonstrated previously (Badosa et al., 2007) that aerosol extinctions there have a negligible effect on UV irradiances at this site. Unfortunately, no measurements of aerosol optical depth were available at the Tokyo site. However, it is likely that they will sometimes exceed 0.5 at wavelength $0.5 \mu \mathrm{m}$ (Chin et al., 2004), and will therefore have appreciable effects on UV irradiances. Profiles of ozone and temperature, which were available from nearby Tsukuba, are representative of the Tokyo site.

\section{Comparison of clear-sky days}

We used the following procedure to identify the clearest summer day (least affected by clouds) at each site. First we restricted the data to days when ozone retrievals were made for scans taken at $\mathrm{SZA}<80^{\circ}$, and for which the noise in the UVA diode signal for these scans is also less than $1 \%$. This subset selected above was further filtered with an objective data-selection algorithm, which placed constraints on diurnal symmetry. The following days, for which there were no turning points other than at noon, and for which the variance was a minimum, were selected:

Lauder, 21 December 2003, Day of Year=355, $\mathrm{SZA}_{\min }=21.6$, ozone $=295 \mathrm{DU}$

Tokyo, 4 July 2004, Day of Year=186, $\mathrm{SZA}_{\min }=12.8$, ozone $=307 \mathrm{DU}$

Measurements of UV irradiances and the calculated UVA tropospheric "transmissions" for Lauder and Tokyo are plotted, and compared as a function of SZA in Fig. 2 for these clear days. These tropospheric transmissions are defined as the measured values divided by calculated values for the same observing conditions, but for clear skies with no aerosols. Thus the transmissions can be interpreted as the Modification Factors associated with cloud and aerosols, analogous to cloud modification factors (CMFs) which have been used previously in the literature (Bodeker and McKenzie, 1996). Despite the Tokyo day being the clearest available for that site there is still significant asymmetry, with the higher irradiances and transmissions occurring during the afternoon. The asymmetries are present in both UVB and in the UVA irradiance, showing that they are not due to changes in ozone. At both sites, the ozone retrieval varied by a maximum of 15 DU (i.e., $5 \%$ of the column) over the selected days. At Lauder ozone increased monotonically over the day, whereas at Tokyo it reached its maximum value for the day at $\sim 10$ a.m. Even on this clearest day, the UVA transmission at Tokyo is $\sim 10 \%$ lower than for Lauder, clearly demonstrating the larger effects of aerosol extinction.

The peak UV irradiances measured on the day selected at each site are close to the maximum valid values for the period. Over the period studied, the highest $\mathrm{UV}_{\text {Ery }}$ value at Tokyo was $0.29 \mathrm{Wm}^{-2}$ (corresponding to UVI=11.6), and the highest at Lauder was $0.32 \mathrm{Wm}^{-2}(\mathrm{UVI}=12.8)$. 


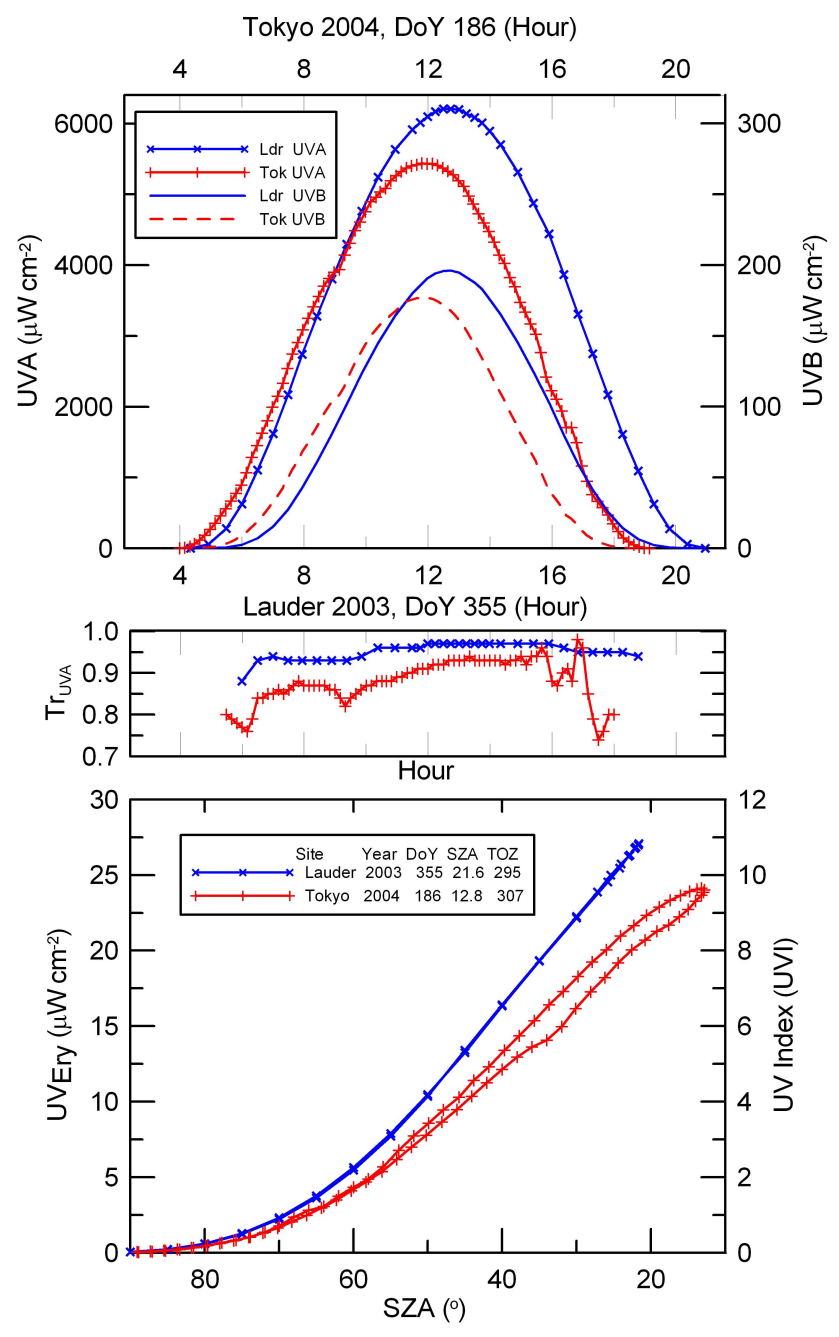

Fig. 2. Measurements of UVA (315-400 nm) and UVB (280$315 \mathrm{~nm}$ ) irradiances over the clearest days at each site (top panel), and corresponding calculated UVA transmissions for the same time periods (middle panel). The corresponding variations in erythemally weighted UV irradiance and UV Index are also shown as a function of SZA (bottom panel).

\section{Comparison of measured spectra}

Because there were few cloudless days, the main analysis for this study compares data from the entire period at Tokyo with data from the period November 2002 to May 2004 at Lauder. By examining the wavelength dependence of the differences we can attribute the causes of the differences, and estimate the contributions from each contributing factor. Over this period there were $\sim 18000$ scans at Lauder and 26000 scans at Tokyo. To avoid effects of intensity changes during the scans, we initially used our criterion for an ozone retrieval; SZA $<80^{\circ}$, noise in the UVA diode signal less than $5 \%$, and for which the cloud transmission is greater than 0.3. This transmission criterion is applied to avoid over-estimates of

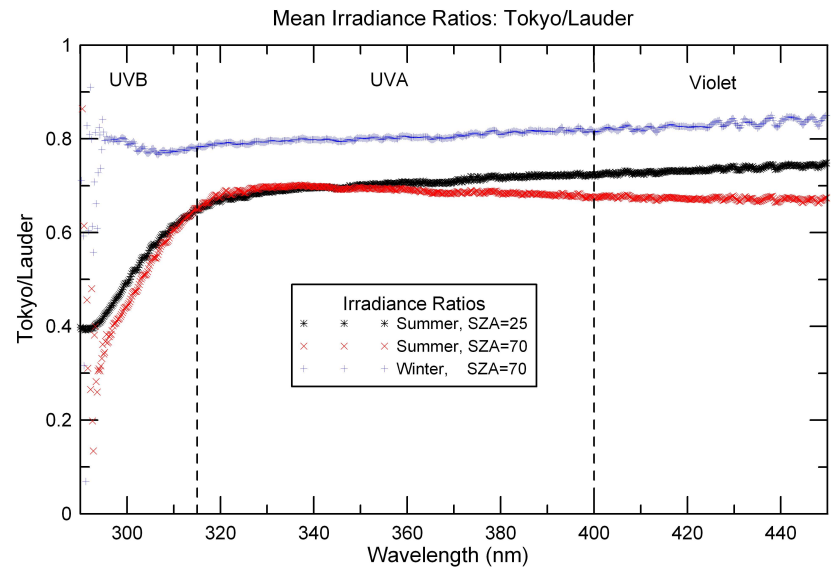

Fig. 3. Spectral ratios of Tokyo irradiances divided by Lauder irradiances for three conditions: summer, $\mathrm{SZA}=25^{\circ}$, and $70^{\circ}$; and winter $\mathrm{SZA}=70^{\circ}$.

ozone due to multiple scattering within clouds, as noted previously (Mayer and Seckmeyer, 1998). The data sets analysed therefore exclude heavily overcast skies. We then examined further restriction of the analysis to scans where the standard deviation of the slit diode signal described above was less than $1 \%$ of its mean value. This latter criterion reduced the number of scans included to $65 \%$ of that with the initial criterion. Since the statistical penalty was relatively small, we decided to restrict our subsequent analysis to scans meeting the tighter selection criterion. The resulting dataset of 6274 scans at Lauder and 8725 at Tokyo includes cloudfree and cloudy-sky scans, but excludes scans where there is non uniform cloud cover in the vicinity of the Sun. Note that since only $30-35 \%$ of all the scans for each site are included, the resulting cloud/aerosol extinctions are not representative of their overall averages.

The spectra measured at each site were then binned by SZA, $\left(5^{\circ}\right.$ steps $\left.\pm 2.5^{\circ}\right)$, and by season. Here "summer" is taken as the 6-month period centred on the summer solstice and "winter" is the complementary 6-month period around the winter solstice. For smaller SZAs, which occur only near the summer solstice, the "summer" period becomes progressively shorter than 6 months. Ratios were then formed to reveal the wavelength dependences of the differences between the two sites. The results are shown in Fig. 3. Although there can be large variations within these bins for larger SZA, we expect these to average out here because we have averaged a large number of scans. If there were a problem from this effect, it would be most pronounced at shorter wavelengths where the atmospheric absorptions are greatest. However, as can be seen for the summer period in Fig. 3, the short wavelength dependence for the $\mathrm{SZA}=70^{\circ}$ bin is similar to that for the $\mathrm{SZA}=25^{\circ}$ bin, where these binning errors are always small. Further, to avoid any possibility of bias from binning in the more detailed analysis that follows (Sect. 5) to attribute 


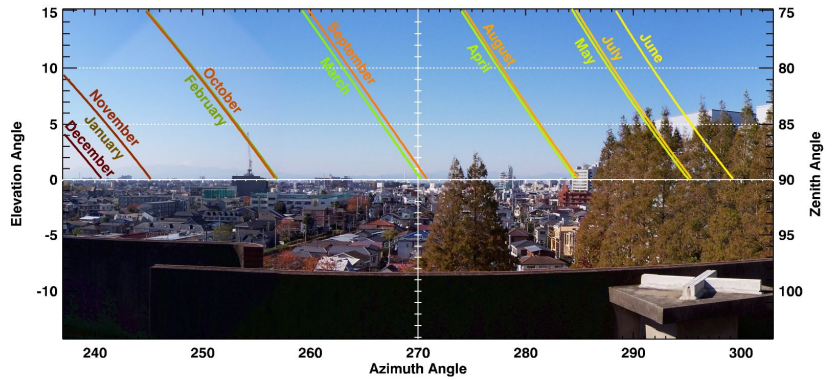

(a)

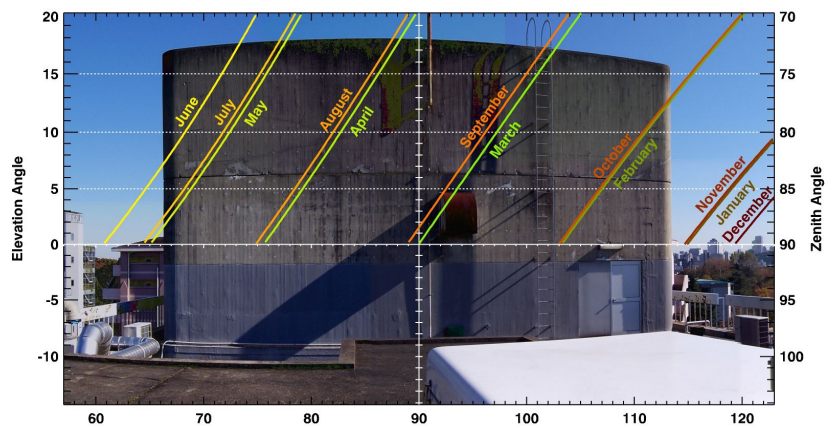

(b)

Fig. 4. Sunrise and sunset horizons viewed from the instrument diffuser at Tokyo. The curves superimposed on the photograph show the path of the sun at twilight on 21 of each labelled month, as functions of the azimuth and elevation/zenith angles. (Upper) View to the East showing a wall which obscured the direct sun for SZA $>72^{\circ}$ in the sunrise periods from February to October. (Lower) View to the West, showing minimal obscuration for the sunset periods. The figures are cylindrical panoramic reconstructions from rectilinear images, with angular uncertainties better than $\pm 0.2^{\circ}$.

causes of changes, we have calculated measured/modelled clear sky ratios for each spectrum, and then binned these ratios of Transmissions from individual spectra at each site.

In all of these ratio spectra there is evidence of residual ozone absorption in the UVB region, and higher frequency "differential" absorption features due to $\mathrm{NO}_{2}$ are visible in the UVA region, especially at $\lambda>420 \mathrm{~nm}$. These features are shown more clearly in Fig. 10, which will be discussed in more detail later.

During the "summer" period, the UV irradiances for high sun, $\mathrm{SZA}=25^{\circ}$ (which is close to noon for the summer solstice period for Lauder) are much smaller at Tokyo than at Lauder (black symbols). The ratio decreases markedly towards shorter wavelengths in the UVB region because of the larger ozone amounts in Tokyo.

During the "summer" period for $\mathrm{SZA}=70^{\circ}$ (red), which is actually a full 6-month period, there is a different wavelength dependency. In the UVB region, the ratio decreases more rapidly than for $\mathrm{SZA}=25^{\circ}$, which can be explained by the longer path length through the ozone at Tokyo, where the total column amount is larger, and the light path through the tropospheric component also becomes longer due to increased scattering. There is also a tendency for the ratio to decrease at longer wavelengths, whereas it tended to increase in that spectral region for the smaller SZA.

In the "winter" period (the complementary 6-month period) for $\mathrm{SZA}=70^{\circ}$, the mean ratio is higher than for the summer period. Approximately $3 \%$ of this difference can be explained by the seasonal progression in Sun-Earth separation (the maximum effect between mid-summer summer and mid-winter is $7 \%$ ). The larger observed difference suggests that extinctions by clouds and aerosols in Tokyo are larger in summer than in winter. In this case the ratios are quite flat through the UVB region. The smaller ozone dependence is expected, since the ozone amounts in winter are similar at both sites (discussed later). However, unlike the situation for $\mathrm{SZA}=70^{\circ}$ in the summer, the ratios in winter tend to become larger at longer wavelengths.

These differences are statistically significant based on the measurement error bars. However, as discussed above, they could be due to differences in the sampling, rather than the well-documented seasonal differences in cloud and aerosol properties mentioned previously. The differences between the three cases could also arise from the effects of horizon obscuration. We used model calculations, assuming isotropically scattered skylight, to estimate the effect of this obscuration as $1-2 \%$, as discussed later. However, the assumption of isotropy may not be valid under polluted conditions such as these.

To investigate whether the observed spectral differences at $\mathrm{SZA}=70^{\circ}$ could be caused by obscuration of the horizons from nearby structures (see Fig. 4), we compared morning results, for which obscuration by a large structure to the East (Fig. 4a) may be more important, with afternoon results, for which there is minimal obscuration (Fig. 4b).

The results of this comparison are summarised in Fig. 5, in which ratios of Tokyo/Lauder irradiance ratios measured at $\mathrm{SZA}=70^{\circ}$ are plotted as a function of season. Morning and afternoon data are plotted separately. The plotted points are the means of all irradiance ratios from $315-450 \mathrm{~nm}$. The UVB component is omitted to minimise effects of noise at the shortest wavelengths, and to avoid effects of seasonal differences in ozone. The vertical bars in the plot show the standard deviations of the ratios for each month. Although the direct beam is unobscured by horizon obstructions in all months for $\mathrm{SZA}<72^{\circ}$, a large area of bright sky in the solar aureole can be blocked early in the day at this site. This blockage occurs throughout the year, but the effect would be largest on clear days when the radiation field is less isotropic. The ratios are much lower in the summer months, showing 


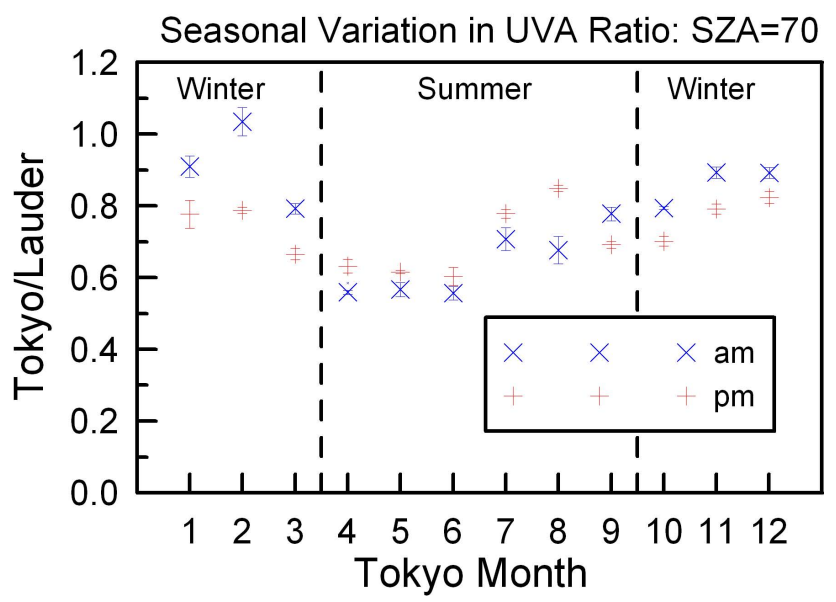

Fig. 5. Seasonal variation in the Tokyo/Lauder irradiance ratios measured at $\mathrm{SZA}=70^{\circ}$, for the morning and afternoon data separately. The plotted points are the means of all irradiance ratios from $315-450 \mathrm{~nm}$. The UVB component is omitted to minimise effects of noise at the shortest wavelengths, and to avoid effects of seasonal differences in ozone. The vertical bars show the standard deviation of the ratios for each month.

that the effects of clouds and aerosols are much larger in Tokyo than at Lauder during the summer, which should be expected because Tokyo experiences its rainy season in summer from mid-June. In winter the ratios are larger, though still usually less than unity. Approximately $7 \%$ of this seasonal change can be explained by seasonal variations in the Sun-Earth separation. With regard to the question of horizon obscuration, differences in these ratios between the morning and afternoon data are of particular interest. During the summer, the afternoon ratios tend to be slightly higher than the morning ratios, which would be consistent with a reduction of cloud and pollution at Tokyo during the day. On the other hand, during the winter, the afternoon ratios tend to be significantly lower than the morning ratios, which would be consistent with Tokyo having mornings that are sunnier, or less polluted than afternoons (diurnal and seasonal variations in these transmission are small at Lauder). Paradoxically, although there is no obscuration of direct sunlight for $\mathrm{SZA}=70^{\circ}$, the effect of horizon obscuration at Tokyo would be more pronounced during sunnier weather due to the greater anisotropy of sky light at those times, and the large component of scattered light in the vicinity of the Sun direction. The a.m./p.m. differences would also be more pronounced at shorter wavelengths. We return to this point in Sect. 9, during discussion of Fig. 13.

Here we estimated the effect of the horizon obscuration at Tokyo by calculating the reduction in diffuse irradiance, expressed as a percentage of the total global irradiance assuming isotropy of skylight. From the preceding discussion, this procedure could potentially underestimate the effect under clear sky condition.

\section{Comparison with models: aerosol and cloud effects}

In order to focus on differences in tropospheric extinctions between these two sites, and to remove the effects of differences in SZA, stratospheric ozone, and Sun-Earth separation, we used the "tuv" radiative transfer model (Madronich and Flocke, 1995) to calculate the clear sky aerosol-free spectrum corresponding to each measurement. The model was recently validated against spectral measurements by the NIWA group at several sites (Badosa et al., 2007). The agreement between the model and NIWA measurement was excellent for clear skies. In this case, however, we are comparing cloud-affected measurements with a clear sky model, so we do not expect such a close agreement.

The ozone values which were used in the model were extracted from the assimilated global ozone data set maintained by NIWA (Bodeker et al., 2001). For both sites, we initially assumed the temperatures and ozone distributions followed those in the US standard atmosphere. A surface albedo of 0.05 was assumed. Although this is slightly higher than a typical value of 0.02 for Lauder, it is probably quite representative of the more built-up environment at Tokyo (McKenzie et al., 1996). These small differences in albedo do not affect the irradiances appreciably. Since the exercise was computationally intensive, and we were concerned only with effects for relatively small air mass factors $\left(\mathrm{AMF}<3\right.$ for $\mathrm{SZA}=70^{\circ}$ ), we used the 2-stream Delta-Eddington approximation in the tuv model runs. More detailed calculations were carried out with the DISORT version of this model for specific cases, as discussed later. We define the "tropospheric transmission" $\mathrm{T}_{\text {Lauder }}, \mathrm{T}_{\text {Tokyo }}$ for Lauder and Tokyo respectively as the ratio of the measured to calculated spectra. The smallest SZA for which data are available year-round at both sites is $\mathrm{SZA}=68^{\circ}$. Time series of these ratios for the $65-70^{\circ}$ SZA bin are shown in Fig. 6. Note that with our data selection criteria, not all cloud conditions are included. At both sites, there is a large day to day variability which is due to the effects of clouds. These seem to be slightly damped for the Tokyo period. For the Lauder periods, the upper envelope of the transmissions is close to unity, and shows little seasonal variability. In contrast, the upper envelope of transmissions at Tokyo is significantly smaller, and shows a much stronger seasonal variability, with smaller transmissions in the summer. We emphasise here that because of the data selection criterion, which required a low variance in UVA during the scans, the derived cloud optical thicknesses in this study cannot be interpreted as representing mean values of the optical depth.

Figure 6 shows that on occasions at Lauder, the transmissions can exceed unity. For the UVB region these can be caused by measurement errors, errors in ozone affecting the model calculations, or by real increases in UV due to reflections from clouds or snow-covered surfaces. An example of the effect of snow is apparent during the winter at Lauder. The effects of snow are largest in the UVB region, where surface albedo is generally less than $2 \%$ 

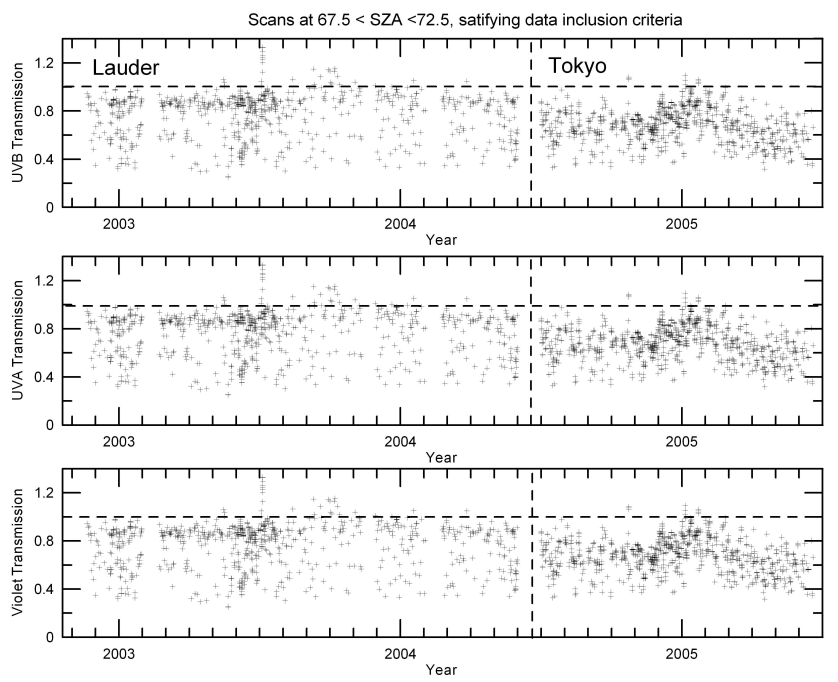

Fig. 6. Time series of tropospheric transmissions for the UV4 instrument during its deployment at Lauder and Tokyo. UVB (top panel), UVA (middle panel) and Violet (bottom panel) for $\mathrm{SZA}=70^{\circ} \pm 2.5^{\circ}$.

at this site (McKenzie et al., 1998), so that increases in surface albedo due to snow cover are largest. For the UVA and violet regions, the ozone factor does not contribute and the albedo effect is smaller. The larger enhancements in the violet region compared with the UVA region are consistent with this being due to cloud enhancements (Pfister et al., 2003). To avoid possible issues arising from the effects of snow cover at Lauder, we analysed data separately for the summer and winter periods.

The SZA dependence of the transmissions in the binned data described previously is shown for three spectral regions in Fig. 7. The transmission is consistently greater at Lauder where there is also a stronger dependence on SZA, and smaller spectral differences. The largest differences between sites and between spectral regions occur at smaller SZA. At the largest SZA available, the transmissions all converge to a value near 0.7. Transmissions tend to be smaller in the UVB region. The differences between Tokyo and Lauder are also more pronounced in the UVB region. They may be attributable to the effect of the aerosols in Tokyo which decrease the contribution of the direct component and redistribute the diffuse radiation. In the SZA range $25^{\circ}<\mathrm{SZA}<30^{\circ}$, the mean transmission at Lauder is greater than 0.9 , whereas the corresponding transmission at Tokyo is 0.7. This implies that the effects of clouds and aerosols are very small at Lauder for the subset of scans selected (for the $65 \%$ of scans where the diode noise is less than $1 \%$ ). The corresponding transmissions if all scans are considered are 0.7 and 0.5 , respectively.

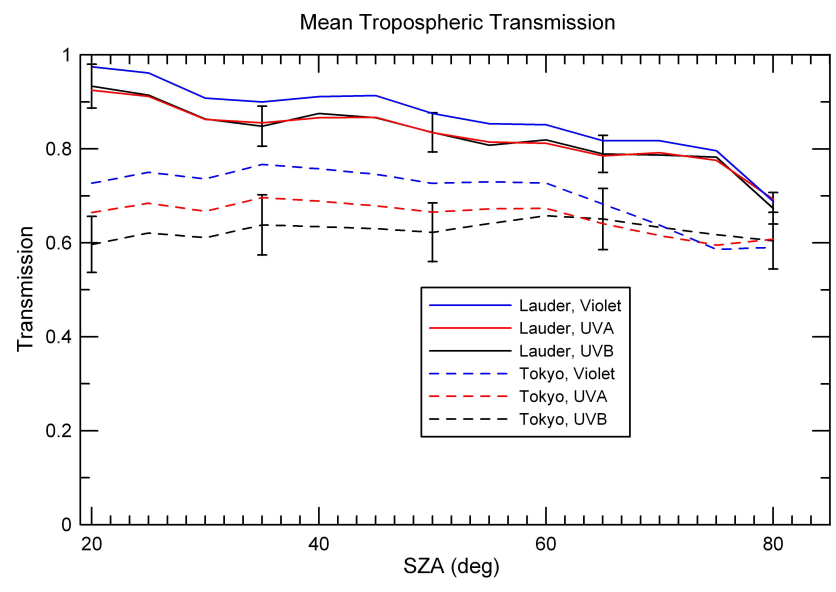

Fig. 7. Tropospheric transmissions at Lauder and Tokyo as functions of SZA. Black: UVB (280-315 nm); Red: UVA (315$400 \mathrm{~nm})$; Blue: violet $(400-450 \mathrm{~nm})$. Solid line, Lauder, Dashed line, Tokyo, period for Lauder: November 2002 to May 2004; Tokyo: June 2004 to June 2005. The $2 \sigma$ uncertainties for Lauder and Tokyo are shown by the error bars on the UVB lines. Uncertainties are similar in the UVA and Violet regions.

\section{Absorptions by trace gases}

Column amounts of trace gases that absorb in the spectral region sampled were derived with an adaptation of the widely used DOAS (Differential Optical Absorption Spectroscopy) method. Previous studies using this method had shown that extinctions by tropospheric aerosols and pollutant trace gases such as $\mathrm{NO}_{2}$ can be neglected at Lauder (Johnston and McKenzie, 1984; Liley, 2006). The excess column amounts of the various trace gases in the Tokyo atmosphere are estimated by least-square fits of the ratio spectra $\left(\mathrm{T}_{\text {Tokyo }} / \mathrm{T}_{\text {Lauder }}\right)$, where $\mathrm{T}_{\text {Tokyo }}$ and $\mathrm{T}_{\text {Lauder }}$ are the tropospheric transmissions defined earlier, and the Lauder site is taken as a pollution-free reference. These ratios are fitted to the relevant basis functions that include the absorption cross sections of the gases in question as well as other known interfering effects, such as absorptions from water vapour, and a basis function to model the filling in of Fraunhofer lines by rotational Raman scattering, known as the "Ring" effect. The retrieval method fits detrended and zero-mean versions of these basis functions to similarly detrended and zero-mean versions of the transmission ratios. We included several trace gases (e.g., $\mathrm{O}_{3}, \mathrm{NO}_{2}, \mathrm{SO}_{2}, \mathrm{OClO}, \mathrm{BrO}$ ), and explored the optimal regions for retrievals by requiring that the fitting error be minimised. Apart from ozone, which is discussed in more detail in Sect. 7, the only two species for which results were statistically meaningful were $\mathrm{NO}_{2}$ and $\mathrm{SO}_{2}$, with optimal retrievals being made in the spectral ranges $425-448 \mathrm{~nm}$ and 300-315 nm, respectively. 


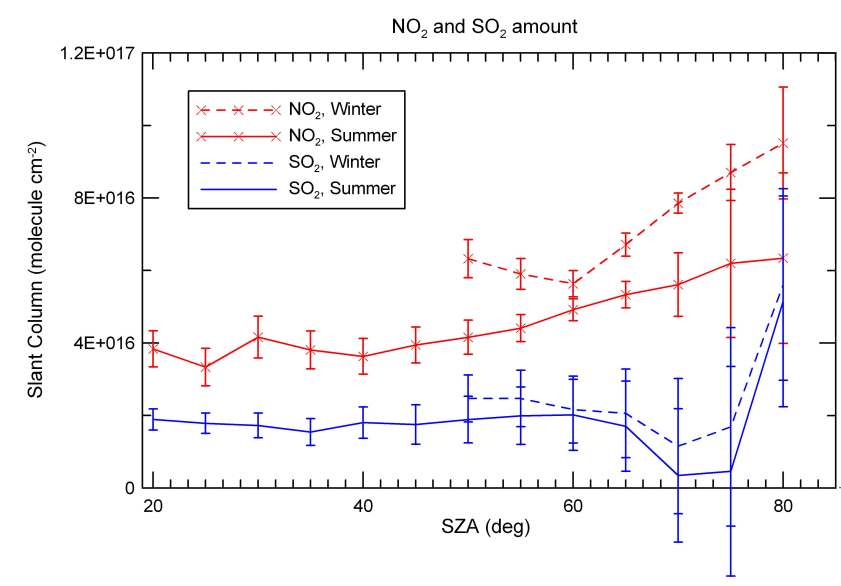

Fig. 8. Slant column amounts of $\mathrm{NO}_{2}$ (red) and $\mathrm{SO}_{2}$ (blue), with error bars as a function of SZA for the mean spectra in the seasons defined previously: summer $\left(20^{\circ}\right.$ to $80^{\circ}$, solid line $)$ and winter $\left(50^{\circ}\right.$ to $80^{\circ}$, dashed line). Error bars show the $2 \sigma$ fitting uncertainties in the retrievals.

The derived $\mathrm{NO}_{2}$ and $\mathrm{SO}_{2}$ slant column amounts over Tokyo for the mean summer and winter spectra are shown in Fig. 8 as functions of SZA. Note that for our definition of winter, the minimum SZA included is $\mathrm{SZA}=50^{\circ}$. For $\mathrm{NO}_{2}$ the retrieved values are larger in winter, and in both seasons they appear to increase as a function of SZA. This apparent increase may however be attributable to the effects of stratospheric $\mathrm{NO}_{2}$, which becomes more important at twilight. The tropospheric path lengths (or air mass factors) also tend to increase with SZA, although under these relatively polluted conditions this dependence is expected to be less than $\sim 20 \%$ over the range of SZA considered. Column amounts of $\mathrm{SO}_{2}$ are smaller, approximately $1.5 \times 10^{16}$ molecule $\mathrm{cm}^{-2}$, and any dependences on SZA or season are not statistically significant for $\mathrm{SZA}<80^{\circ}$.

These column amounts derived in this manner should not be considered as representing mean values. Rather, they represent the trace gas amounts derived from the mean spectra. An absorption in a cloud-free spectrum. In practice, the absorptions by trace gases tend to be larger at times of low transmission, probably as a result of increased scattering within the tropospheric light path under such conditions. Consequently, the column amounts in Fig. 8 are smaller than the true mean values. Further, as noted below, we believe the $\mathrm{NO}_{2}$ values are systematically low by approximately $12 \%$ (corresponding to an error of $\sim 0.7 \times 10^{16}$ molecule $\mathrm{cm}^{-2}$ in the mean value).

The short term variability in $\mathrm{NO}_{2}$ is shown in Fig. 9, with the same data acceptance criteria as used in Fig. 8, except that scans with low cloud transmissions were also accepted. By limiting to $\mathrm{SZA}<80^{\circ}$ we minimize contributions from stratospheric $\mathrm{NO}_{2}$. As a validation check of the retrieval method, we also show slant column amounts of $\mathrm{NO}_{2}$ derived using

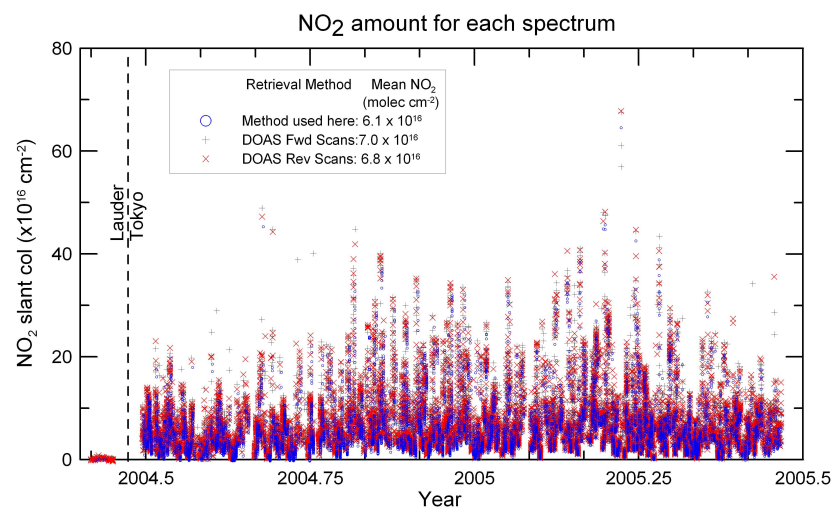

Fig. 9. Slant column amounts of $\mathrm{NO}_{2}$ for each spectrum plotted as a time series for the whole Tokyo period, and for the period at Lauder immediately before deployment to Tokyo.

the standard, well-validated (Hofmann et al., 1995) DOAS technique, as described by Johnston and McKenzie (1984, 1989). For these we additionally required that the residual error in fitting is below an acceptance limit that corresponds to a 2- $\sigma$ fitting error of $2.5 \times 10^{16}$ molecule $\mathrm{cm}^{-2}$ in $\mathrm{NO}_{2}$. Typically, the residual error is much smaller than this limit, giving a mean error of $0.5 \times 10^{16}$ molecule $\mathrm{cm}^{-2}$. This fitting-error criterion had little effect on the mean values, but did result in rejection of several extreme values. The wavelength range and the absorptions cross sections for $\mathrm{NO}_{2}$ were the same in both methods.

There is a close correspondence in variabilities between the two $\mathrm{NO}_{2}$ retrieval methods, but he mean value by the method of Fig. 8 was $6.1 \times 10^{16}$ molecule $\mathrm{cm}^{-2}$, approximately $12 \%$ less than the standard DOAS value $6.9 \times 10^{16}$ molecule $\mathrm{cm}^{-2}$. A possible bias error of up to $0.5 \times 10^{16}$ molecule $\mathrm{cm}^{-2}$ can be attributed to noise in the irradiance spectra. This is introduced when applying the calibration, which involves a scan of a lamp for which the intensity is very much less than skylight in the wavelength range of the $\mathrm{NO}_{2}$ retrievals. There is an additional uncertainty of $0.5 \times 10^{16}$ molecule $\mathrm{cm}^{-2}$ attributable to the maximum wavelength misalignment of $0.01 \mathrm{~nm}$. Differences between the two retrieval methods are therefore within the combined uncertainty of the two methods.

Figure 9 also includes results from Lauder for the $\sim 2$ week period prior to the deployment to Tokyo. These clearly demonstrate the low $\mathrm{NO}_{2}$ values at Lauder, and the low retrieval noise. Results are shown separately for the forward and reverse scans. Note that because the rejection criteria are applied separately in each case (i.e., to the forward scans, reverse scans and their mean), the subsets selected are slightly different. In most cases, where all three retrievals are available, there is satisfactory agreement. Most of the remaining variability between the retrievals is due to intensity changes during the scan period, which can produce spectral features that correlate with $\mathrm{NO}_{2}$ absorption features. 


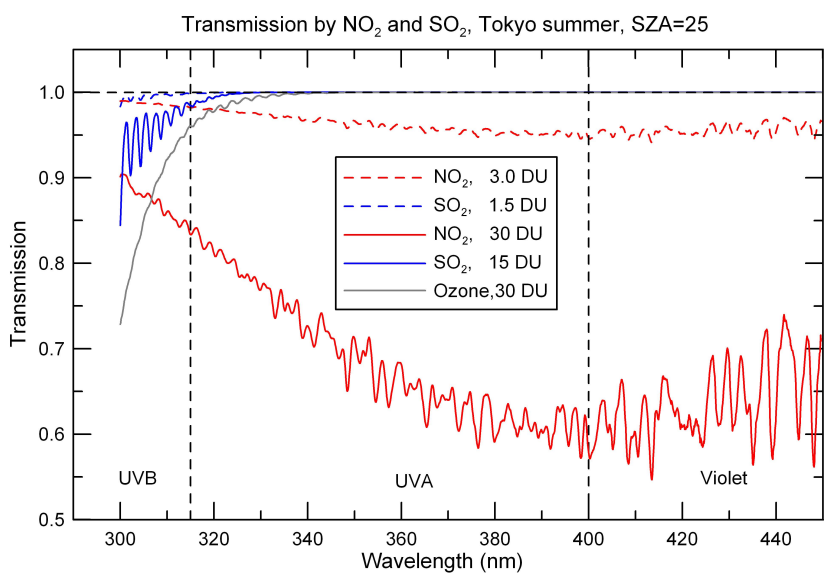

Fig. 10. Tropospheric extinctions at $\mathrm{SZA}=25^{\circ}$ for $\mathrm{NO}_{2}$ and $\mathrm{SO}_{2}$ slant column amounts of $3 \mathrm{DU}$ and $1.5 \mathrm{DU}$, respectively, which are similar to the mean values observed (but are approximately $50 \%$ larger than the values in Fig. 8), and for the extreme cases where slant column amounts are a factor of 10 greater than the mean. For comparison the calculated absorption from $30 \mathrm{DU}$ $\left(8.07 \times 10^{17}\right.$ molecule $\left.\mathrm{cm}^{-2}\right)$ of ozone, which is approximately $10 \%$ of the atmospheric burden, is also plotted.

On some Tokyo days the $\mathrm{NO}_{2}$ column amount can dramatically exceed the mean values. For example, on some days column amounts were close to $70 \times 10^{16}$ molecule per $\mathrm{cm}^{2}$, which exceeds the mean value by a factor of $\sim 10$. These extreme values tend to occur under heavily overcast conditions. As previously noted for the mean values, the baseline values of $\mathrm{NO}_{2}$ in this plot also tend to be larger in winter than summer.

The column amounts can in principle be related to vertical column amounts, if the effective air mass factors are known (Honninger et al., 2004); and then to concentrations, if the thickness of the boundary layer is known (e.g., from lidar observations). The vertical column amounts are approximately half of the slant column amounts measured at $\mathrm{SZA}=60^{\circ}$, and the resulting concentrations are quite plausible (Y. Morino, personal communication, Centre for Environmental Studies, Tsukuba, Japan). However, the details of this retrieval are outside the scope of the present work, and will be discussed elsewhere. Here we are concerned only with the effect of the slant column amounts on the radiation received at the surface.

We are unable to apply the standard DOAS technique to $\mathrm{SO}_{2}$ retrievals in the steeply sloping UVB region, and we cannot exclude the possibility that they too have systematic errors. Work is in progress to extend our DOAS technique to this spectral region.

The calculated spectral absorption signatures caused by similar amounts of tropospheric $\mathrm{NO}_{2}$ and $\mathrm{SO}_{2}$ are shown in Fig. 10. For the seasonal means in $\mathrm{NO}_{2}$ and $\mathrm{SO}_{2}$ column amounts, the absorptions are relatively small. Their peak absorptions are 5\% in the UVA and $2 \%$ in the UVB regions respectively for the (slightly less for the mean spectra in Fig. 8). However, in the extreme case, where the slant column amount of $\mathrm{NO}_{2}$ is a factor of 10 greater ( $70 \times 10^{16}$ molecule $\left.\mathrm{cm}^{-2}\right)$, the absolute absorption is strong. Absorption by $\mathrm{NO}_{2}$ can exceed $30 \%$ in the UVA region, and even in the UVB region, where its cross section is smaller, the absorption is $\sim 10 \%$. Retrievals of $\mathrm{SO}_{2}$ from individual spectra are noisier than for $\mathrm{NO}_{2}$. However, peak amounts ten times as large as the mean values again occur. Further, the concentrations of pollutant trace gases in this region appear to depend largely on local meteorological conditions and transport from the major source regions (Shirai et al., 2007 ), so the day to day variability in $\mathrm{SO}_{2}$ could be similar to that for $\mathrm{NO}_{2}$. In that case, absorptions by $\mathrm{SO}_{2}$ could exceed $10 \%$ at some wavelengths in the UVB region. However, we note that such $\mathrm{SO}_{2}$ columns are more than twice as large as recently reported over NE China (Krotkov et al., 2008). The observed mean absorptions by $\mathrm{NO}_{2}$ are comparable with those observed at other metropolitan areas, such as in Moscow (Chubarova, 2008).

It had been our intention to additionally determine whether there were any unidentified spectral absorption features, possibly attributable to the cocktail of organic aerosols that is expected to be present in Tokyo. While there are significant remaining absorptions due to factors other than the retrieved trace gases, no definitive and consistent residual spectral characteristic could be identified. Our inability to identify any such effects suggests that they are rather small or, alternatively, that the overall effect of these absorbers has little overall spectral signature - albeit perhaps due to overlap of many different absorbers with uncorrelated absorption features.

\section{Effects of profile differences, and their interaction with aerosols}

Despite the fact that the effects of ozone should already be removed by forming the ratios of measured to modelled irradiances for each site, residual absorptions by ozone were still evident in the trace gas retrievals. We investigated whether these could be attributed to a larger fraction of ozone being in the troposphere at Tokyo, since it has been shown previously that, on a per molecule basis, ozone absorbs more efficiently in the troposphere than in the stratosphere (Bruhl and Crutzen, 1989). This effect arises from two factors. Firstly, for small solar zenith angles the geometric path length through tropospheric ozone is increased by multiple scattering. Secondly, at the warmer temperature in the troposphere, the absorption cross section of ozone is larger. As the SZA increases, the first of these factors tends to act in the opposite sense because the tropospheric air mass for the direct beam then becomes large, and multiple scattering tends to reduce the effective path length through the troposphere. 

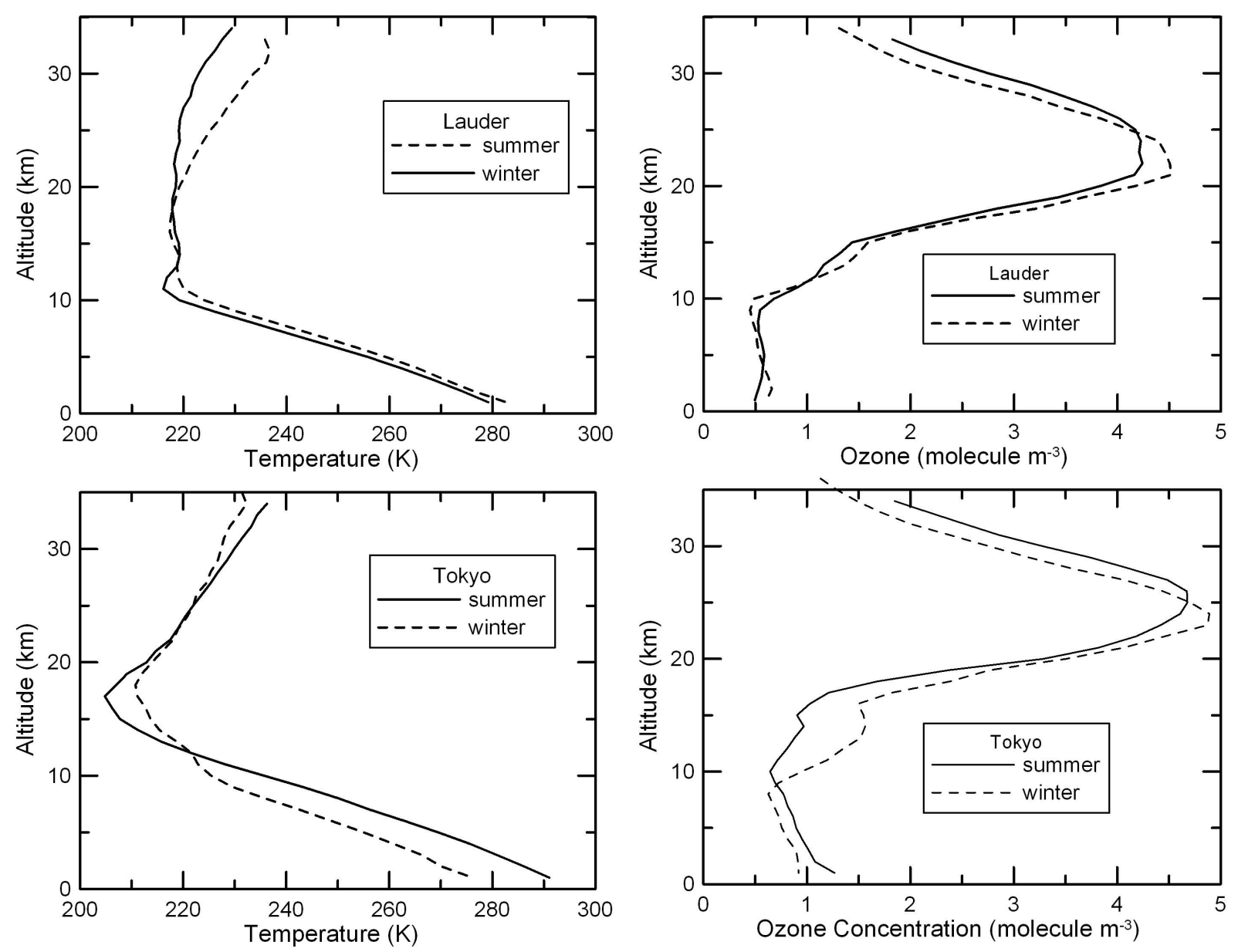

Fig. 11. Comparison of ozone profiles (left) and temperature profiles (right) at Lauder (top) and Tokyo (bottom). The profiles for Tokyo were obtained from balloon sonde flights at Tateno, near Tsukuba, Tokyo.

Previous work has shown that geographical and seasonal differences in the ozone and temperature profiles can have significant effects on UV irradiances (Badosa et al., 2007; Kazantzidis et al., 2005; McKenzie et al., 2003). These may be especially important in Tokyo, since ozonesonde flights from nearby Tsukuba have shown very large enhancements of ozone in the boundary layer, especially during the summer, that are characteristic of urban air pollution (Oltmans et al., 2004). The large aerosol extinctions in Tokyo can exert an additional effect by increasing the effective tropospheric path length, which in turn can lead to increased absorption by tropospheric ozone, as noted by Kerr and Davis (2007).

The mean conditions encountered at each site are shown in Table 2. The effects of differences in the ozone and temperature profiles between Lauder and Tokyo were modelled using the DISORT 8-stream version of the tuv model. First we extracted the mean summer and winter profiles at each site for the periods of study from a recently compiled database (Hassler et al., 2008). The mean profiles are shown in Fig. 11. As expected, the tropospheric burden of ozone is significantly larger at Tokyo than at Lauder. There are also significant differences in the temperature profiles, with lower temperatures and larger seasonal mean difference at tropopause heights over Tokyo than at Lauder. In the lower troposphere there is a much larger seasonal difference at Tokyo than at Lauder. We then compared irradiances calculated using the Lauder profiles with those calculated with the profiles that were appropriate for Tokyo. For both sites, we used the total column ozone amounts as measured at Lauder. Expressing the optical depth in terms of the Ångstrom relation $\left(\tau=\beta \lambda^{-\alpha}\right)$, the calculation was repeated for a range of aerosol optical depths $(\beta$, specified at $1 \mu \mathrm{m})$, with a $1 / \lambda$ wavelength dependence $(\alpha=1)$. In all cases we assumed an aerosol single scattering albedo $(\omega)$ of 0.95 , an aerosol asymmetry factor $(\mathrm{g})$ of 0.61 , and a surface albedo of 0.05 . Our $\omega$ was taken to represent the effective value for the combined cloud/aerosol effect. This is somewhat lower than recent studies have indicated for urban aerosols alone. For example, $\omega \leq 0.7$ have been measured in urban environments in Europe (Bais et al., 2005; Petters et al., 2003). 
Table 2. Comparison of the mean conditions (mean day-of-year, and vertical columns of ozone, $\mathrm{NO}_{2}$, and $\mathrm{SO}_{2}$ ) at Lauder and Tokyo for the spectra analysed at $\mathrm{SZA}=25^{\circ}$ (summer only), and $\mathrm{SZA}=70^{\circ}$ (summer and winter). See Fig. 7 for uncertainties in $\mathrm{NO}_{2}$ and $\mathrm{SO}_{2}$ retrievals. The conversion from slant column amount to vertical column amounts assumed air mass factors of 1.5 and 2.5, respectively at the two SZAs. One Dobson Unit (DU) corresponds to a vertical column amount of $2.69 \times 10^{16}$ molecule $\mathrm{cm}^{-2}$.

\begin{tabular}{|c|c|c|c|}
\hline \multirow{2}{*}{$\begin{array}{l}\text { Season } \\
\text { Solar Zenith Angle (SZA) }\end{array}$} & \multicolumn{2}{|c|}{ Summer } & \multirow{2}{*}{$\begin{array}{r}\text { Winter } \\
70^{\circ}\end{array}$} \\
\hline & $25^{\circ}$ & $70^{\circ}$ & \\
\hline \multicolumn{4}{|l|}{ Day of Year } \\
\hline Lauder & 359 & 12 & 166 \\
\hline Tokyo & 160 & 177 & 362 \\
\hline \multicolumn{4}{|l|}{ Ozone column (DU) } \\
\hline Lauder & 290.0 & 287.7 & 300.1 \\
\hline Tokyo & 320.8 & 320.1 & 301.5 \\
\hline \multicolumn{4}{|l|}{$\mathrm{NO}_{2}$ column (DU) } \\
\hline Lauder & 0 & 0 & 0 \\
\hline Tokyo & 1.0 & 0.7 & 1.0 \\
\hline \multicolumn{4}{|l|}{$\mathrm{SO}_{2}$ colum (DU) } \\
\hline Lauder & 0.0 & 0.0 & 0.0 \\
\hline Tokyo & 0.3 & 0.1 & 0.1 \\
\hline
\end{tabular}

In the UV-A region the effects of these profile differences are small. In the UV-B region their effect was to reduce irradiances in Tokyo compared with Lauder. These reductions were largest for small SZA in the summer, when the $\mathrm{UV}$ is most intense (see Table 3). However, at wavelengths shorter than $\sim 300 \mathrm{~nm}$, the effect of profile differences becomes larger for $\mathrm{SZA}=70^{\circ}$ than for $\mathrm{SZA}=25^{\circ}$, as shown in Fig. 12. At these shorter wavelengths, the effects of interactions between the profiles and aerosol also become more important. As the aerosol burden increases, the radiative effect of the profile differences between Lauder and Tokyo is amplified. At the shortest wavelengths, particularly for $\mathrm{SZA}=70^{\circ}$, there is a suggestion of a reversal, where the effect of these profile differences causes an increase in the ratio as the wavelength decreases - though it must be emphasised that both the model calculations and the measurements are subject to larger uncertainties for these conditions. At twilight the effects of these changes in profile are smaller, and for $\mathrm{SZA}>90^{\circ}$ they can even reverse sign at shorter UVB wavelengths (not shown). However, this is of little importance because at twilight the total irradiance at these wavelengths is very small. Finally, we note that the effects of ozone profile differences and temperature profile differences do not add linearly. At the smaller SZA $\left(\mathrm{SZA}=25^{\circ}\right)$, the combined effect is larger than the sum of the two individual effects. Conversely, at the larger SZA $\left(\mathrm{SZA}=70^{\circ}\right)$, the combined effect is smaller than the sum of the two individual effects (not shown).

\section{Effects of Ozone Temperature Profiles}
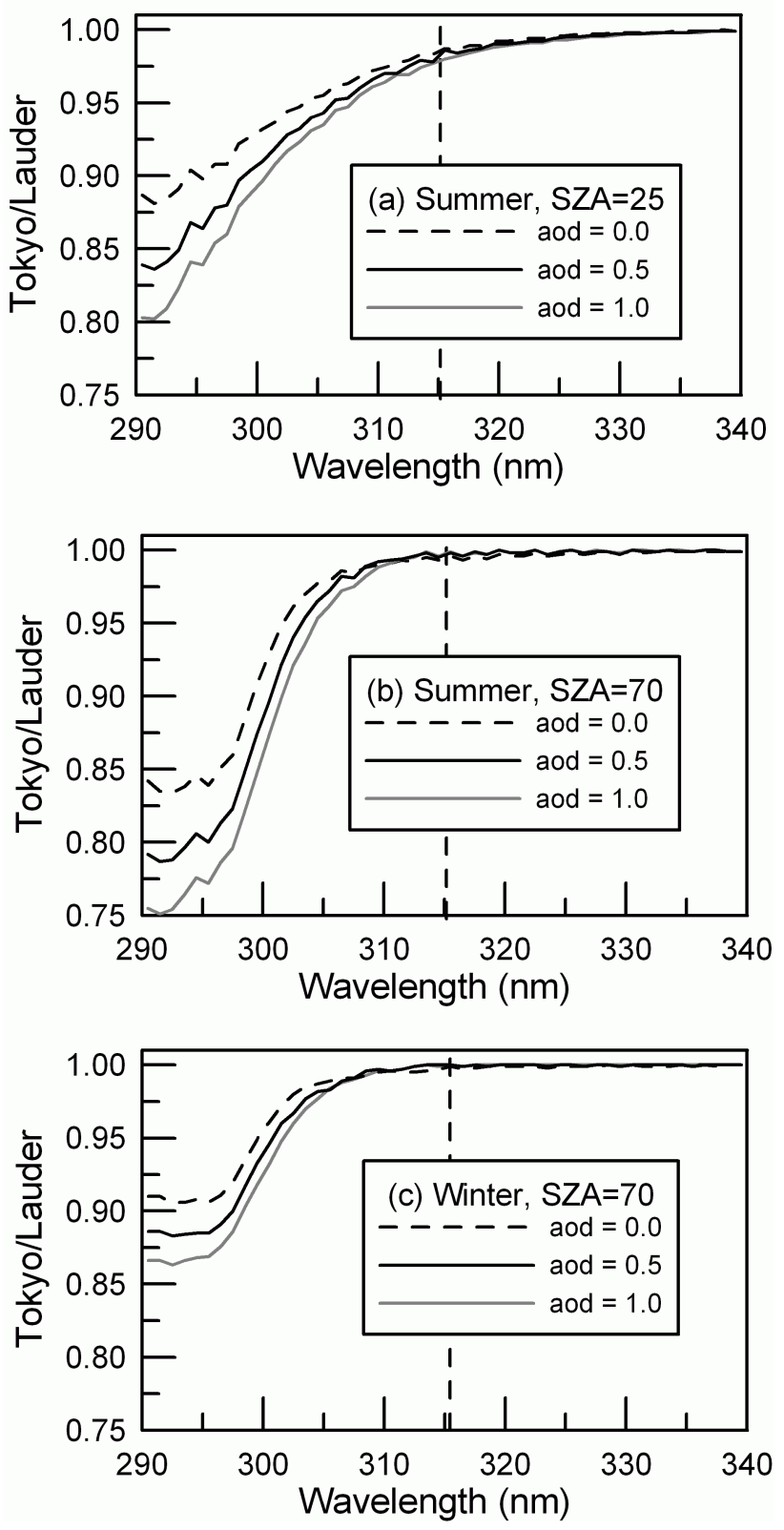

Fig. 12. Calculated effects of differences in ozone and temperature profiles between Lauder and Tokyo. In all cases, the total ozone amounts were as measured at Lauder (see Table 2).

\section{Comparing modelled and measured UV spectral irra- diances}

To check our overall understanding of the processes, we compared averages of the measured spectral irradiance ratios between Tokyo and Lauder (shown previously, in Fig. 3) with corresponding modelled ratios calculated from the tuv radiative transfer model using DISORT with 8 -streams. Although the measured spectra include the effects of clouds, the 
Table 3. Mean percentage differences in UVB and UVA between Tokyo and Lauder and the inferred attribution effects. Results are shown for summer (SZA: $25^{\circ}$ and $70^{\circ}$ ) and winter (SZA: $70^{\circ}$ ). The effect of clouds and aerosols (E9) is defined as the remaining extinction after all identified factors have been considered, $(\mathrm{E} 9=\mathrm{Obs}-(\mathrm{E} 1+\mathrm{E} 2+\mathrm{E} 3+\mathrm{E} 4+\mathrm{E} 5+\mathrm{E} 6+\mathrm{E} 7+\mathrm{E} 8))$. The uncertainty is the $2 \sigma$ quadrature sum from the measurements at both sites.

\begin{tabular}{lllllccc}
\hline Effects & Spectral Range & \multicolumn{3}{c}{ UVB } & \multicolumn{3}{c}{ UVA } \\
\hline & Solar Zenith Angle (SZA) & \multicolumn{2}{c}{ Summer } & Winter & \multicolumn{2}{c}{ Summer } & Winter \\
\hline & & $25^{\circ}$ & $70^{\circ}$ & $70^{\circ}$ & $25^{\circ}$ & $70^{\circ}$ & $70^{\circ}$ \\
& Observed & $-39 \pm 11$ & $-38 \pm 11$ & $-22 \pm 11$ & $-30 \pm 10$ & $-31 \pm 10$ & $-19 \pm 10$ \\
E1 & Ozone column & -9 & -16 & -0.7 & 0 & 0 & 0 \\
E2 & $\mathrm{O}_{3}$ \& T Profiles & -3.5 & -0.1 & -0.1 & -0.2 & 0 & 0 \\
E3 & Sun-Earth Distance & -2.6 & +2.2 & +2.5 & -2.6 & -2.2 & +2.5 \\
E4 & Altitude & -1.7 & -1.9 & -1.9 & -1.0 & -1.4 & -1.4 \\
E5 & Horizon obscuration $_{\text {E6 }}$ & -1.5 & -1.9 & -1.9 & -1.0 & -1.0 & -1.0 \\
E7 & $\mathrm{SO}_{2}$ column & -0.9 & -0.7 & -1.1 & -1.5 & -1.7 & -2.5 \\
E8 & Trop O O $/$ /Aerosol inter & -0.5 & -0.1 & -0.4 & -0.1 & 0.0 & -0.1 \\
E9 & Clouds/Aerosols & $-18 \pm 11$ & -1.0 & -1.0 & 0.0 & +0.0 & +0.0 \\
& & & & $-17 \pm 11$ & $-24 \pm 10$ & $-25 \pm 10$ & $-17 \pm 10$ \\
\hline
\end{tabular}

calculations were carried out for cloud-free conditions, and we attempted to simulate the differences due to the combined effects of clouds and aerosols. The calculations included the effects of differences in altitude, and Sun-Earth separation, but they excluded the effects of horizon obscuration at Tokyo. The inputs to the model calculations are as listed in Table 2, and we used the vertical profiles for ozone and temperature profiles shown in Fig. 11. Baseline calculations were carried out for each site assuming aerosol free conditions and a Lambertian surface albedo of 0.05 (independent of wavelength). No trace gases were included for Lauder, but for Tokyo we included the effects of absorptions by $\mathrm{NO}_{2}$ and $\mathrm{SO}_{2}$. We investigated the sensitivities to changing the Ångstrom parameters $(\beta$ and $\alpha$ ), and surface albedo in Tokyo. In all cases, we assumed an effective single scattering albedo of $\omega=0.95$, and an asymmetry parameter $\mathrm{g}=0.61$ for these cloud/aerosol effects. Examples of these comparison are shown in Fig. 13.

For $\mathrm{SZA}=25^{\circ}$ in the summer, the measured ratios are well simulated by the model between $330 \mathrm{~nm}$ and $450 \mathrm{~nm}$ for an assumed aerosol optical depth, $\tau_{1 \mu \mathrm{m}}=0.5$. At wavelengths shorter than $300 \mathrm{~nm}$, the measured ratios become progressively higher than the calculated ratios.

For $\mathrm{SZA}=70^{\circ}$ in the summer, the measured ratios are well simulated by the model down to $300 \mathrm{~nm}$, for the lower optical depth of $\tau_{1 \mu \mathrm{m}}=0.2$. At shorter wavelengths the measured ratios are again larger than the calculated ratios.

For $\mathrm{SZA}=70^{\circ}$ in the winter, the measured ratios do not match the calculated ratios, possibly because of the confounding effect of the nearby buildings. While there is reasonable agreement at the longest wavelengths with the calculated ratios for $\beta=0.1$, measured values fall further and further below the calculated ratios throughout most of the UVA and UVB range. This tendency for measured ratios to be- come smaller at shorter wavelengths may be a consequence of obscuration of scattered light by the building (see Fig. 4), since its effect is larger in the winter when it is less cloudy and the scattered light component becomes a progressively larger fraction of the total at shorter wavelengths.

To understand this better, measured ratios for the morning and afternoon data respectively have been included in Fig. 13. Differences between the morning and afternoon ratios are relatively small for the summer conditions. However, there are significant differences between the morning and afternoon results in the winter. In the afternoon data, the ratios are lower than in the morning. In neither case is the spectral signature consistent with the model results. The best-fit optical depth is also significantly lower for these winter morning values at $\mathrm{SZA}=70^{\circ}$ than for the other cases. These findings suggest that Tokyo skies tend to be clearest during the winter morning periods, and in that case the radiation field is less isotropic and therefore more affected by the horizon blockage in the vicinity of the Sun. A comparison of morning and afternoon results revealed that tropospheric transmissions at Tokyo were indeed larger during the winter mornings, as shown previously in Fig. 5.

In all cases, there is a tendency for the measured ratios to exceed the modelled ratios at the shortest wavelengths. Sensitivity tests showed that variations in the surface albedo and the wavelength-dependence of aerosol extinction at Tokyo had only small effects on the ratios shown in Fig. 13. For example, if the surface albedo at Tokyo is increased from 0.05 to 0.10 , the UVB ratios at $\mathrm{SZA}=70^{\circ}$ increase by less than $1 \%$. Similarly, if the Angstrom wavelength exponent of aerosol extinction $(\alpha)$ is reduced from its default value of 1.0 to 0.8 , the increase in the UVB ratios is also only $\sim 1 \%$. However, as noted above, the range of Ångstrom wavelength 
Measured versus Calculated Irradiance Ratios

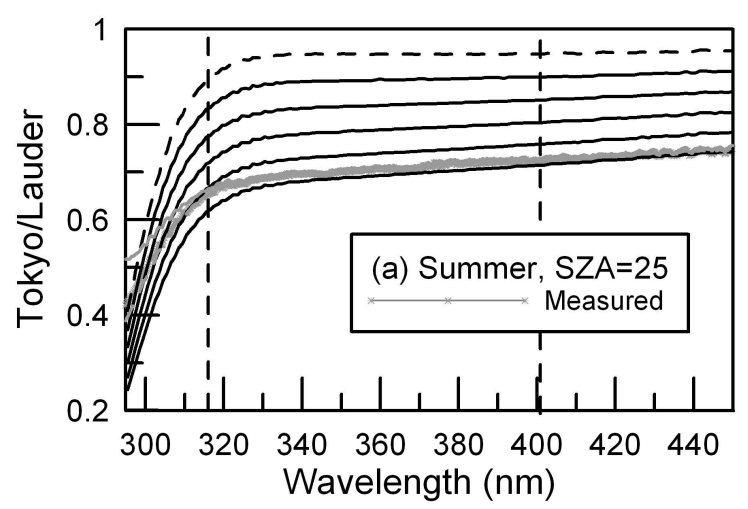

O. 0

O. 1

0.2

0.3

O. 5

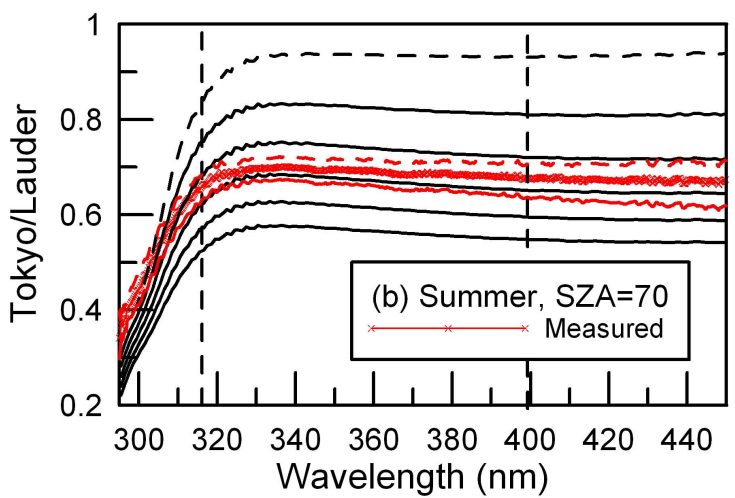

0.0

0. 1

0.2

0.3

0.4

0.5

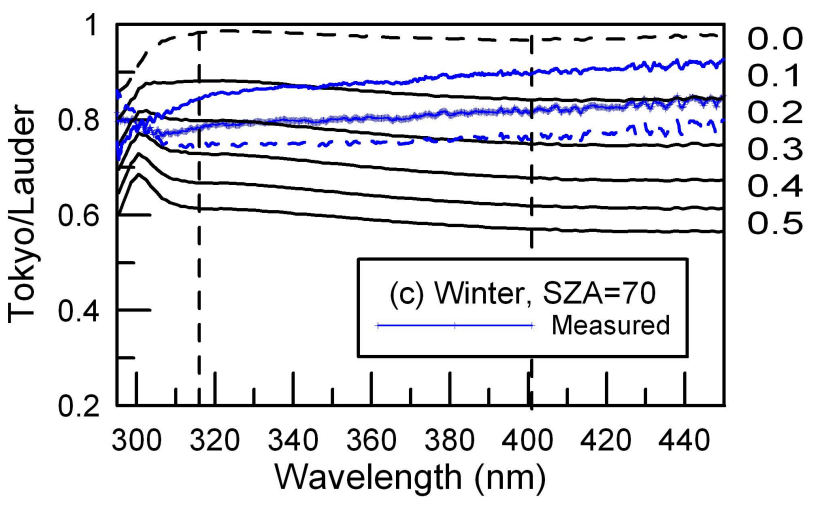

Fig. 13. Comparison between measured and calculated spectral ratios for Tokyo/Lauder for the same cases as shown in Fig. 3 (a) summer, $\mathrm{SZA}=25^{\circ}$, (b) summer, $\mathrm{SZA}=70^{\circ}$, (c) winter, $\mathrm{SZA}=70^{\circ}$. The calculated curves are labelled on the right by their optical depth at $1 \mu \mathrm{m}(\beta)$. The solid and broken coloured lines around the measured values for $\mathrm{SZA}=70^{\circ}$ show the measured ratios for the morning and afternoon data, respectively.

exponents $(\alpha)$ and single scattering albedos could differ greatly from the values shown in Fig. 13. Values of $\alpha$ from 0.6 to 2.0 have been reported in the literature at polluted sites. If higher $\alpha$ values had been used in combination with low values of the single scattering albedo (e.g., 0.7), then the effects on irradiances can be substantially larger for any given optical depth (Bais et al., 2005). We carried out further RT calculations to investigate this further, using a wider range of $\alpha$ ( 0.6 to 2$)$ and a wider range of single scattering albedo (0.6 to 0.95 ), and have found the behaviour in winter is more consistent with using a larger value of $\alpha$ and a corresponding smaller value of $\beta$. Unfortunately, we were unable to find a realistic combination of parameters to match the observations, which we still think are more influenced by horizon obscuration during the sunnier winter period.

The aerosol conditions that result in best agreements between model and measurement are different for each of the three cases. Significant differences in aerosols are plausible, since the periods are different (e.g., seasonality of aerosols, effects of rainy season). However, even allowing for these differences there are several features in the measured ratios which are not present in the model. For example, in all three cases, the measured ratios are larger than the model at the shortest wavelengths. These differences are reminiscent of those seen in Fig. 12, but are not present in the model calculations in this case because differences in total column ozone amounts (see Table 2) swamp those due to profile differences. The effect is also in the opposite sense to what would be expected if there were unidentified absorbers, such as from organic aerosols, in Tokyo. The divergence between model and measurement, with relatively higher measured values in the UVB region compared with the UVA region leads us to conclude that any effects of unidentified organic aerosols that preferentially absorb in the UVB region are not large. The discrepancies noted here are perhaps not surprising, since we have attempted to model the observed ratios for all sky conditions using a clear-sky model. Even small differences in cloud cover could have a marked effect. The behaviour at the shortest wavelengths, where measured ratios are higher than modelled ratios, is unexpected and remains unexplained.

\section{Conclusions}

During the summer, mean UVB irradiances at Tokyo are approximately $40 \%$ less than at Lauder for the same solar zenith angle. These differences are slightly smaller in the winter, and in the UVA region.

The effects of pollution in Tokyo impose large reductions in UV irradiances compared with those at the pristine Lauder site. The reductions in UV at Tokyo become progressively larger as the wavelength decreases through the UVA and UVB regions. The difference of the mean values between Lauder and Tokyo in the UVB and UVA for two SZAs in summer and one in winter are summarised respectively in Table 3. Note that the combined effect of the individual factors is not the same as the overall transmission shown in Fig. 7. The differences are at times close to the combined uncertainty of the measurements $( \pm 11 \%)$. However, the chief cause for the discrepancy is not measurement error, but is due to the fact that the RT model used in that figure did not 
include all of the effects discussed in the table. In particular, it was run with only 2 -streams and excluded the effects of differences in ozone and temperature profiles, and the interactions with aerosols, absorptions by $\mathrm{NO}_{2}$ and $\mathrm{SO}_{2}$, and horizon obscuration.

The effects of Sun-Earth differences, altitude, ozone, profile differences, and tropospheric trace gases were all included in Fig. 13, and further sensitivity tests with the tuv radiative transfer model failed to identify any modification that could have improved the agreement significantly. The effect of horizon obscuration remains as a likely candidate for the remaining discrepancy between model and measurement. Its effect was estimated by calculating the reduction in diffuse radiation field, which was assumed to be isotropic. The reduction is expressed as a fraction of the total radiation field. For the solar zenith angles chosen, the direct beam is never obscured. There are limitations to this approach. Firstly, the diffuse fraction is a function of aerosol optical depth, which was not measured directly - we simply assumed an optical depth of 0.2 at Tokyo for this calculation. Secondly, although the diffuse radiation field tends to be more isotropic in the UV region, there is still a relatively large fraction from the region of the sky surrounding the Sun (the aureole). An accurate representation of these effects is complex, and since the overall correction from horizon obscuration is rather small, we did not include these detailed effects.

After all known effects were taken into account, any remaining unexplained differences were attributed to the effects of aerosols and clouds. Referring to Table 3, it can be seen that these cloud/aerosol effects are the largest contributors to the differences in UV between Tokyo and Lauder. In the UVA region, the effects of clouds and aerosols seem to be smaller in the winter than in the summer. However, in the UVB region, their contribution is similar in summer and winter, and does not depend strongly on SZA. In the UVB region, the next most important factors are the differences in column ozone and its vertical profile. These are important only in the summer months. The next most important factor is the differences in Sun-Earth separation, which acts in the opposite sense in winter. The effect of horizon obscuration is small and is comparable with the differences that are due to differences in altitude. Both of these effects are slightly greater at larger SZA. The effects of $\mathrm{NO}_{2}$ and $\mathrm{SO}_{2}$ are small for the mean amount. The effects of $\mathrm{NO}_{2}$ are larger in the UVA region, while the effects of $\mathrm{SO}_{2}$ are larger in the UVB region. However, for the peak amounts, which can be $\sim 10$ times these mean values, the decreases in irradiances can be appreciable.

This study reinforces previous research that has shown UV intensities in New Zealand to be relatively large compared with corresponding latitudes in the northern hemisphere. In this case, we have demonstrated its higher tropospheric transmission is an important factor. While the cleaner atmosphere in Lauder New Zealand is undoubtedly beneficial for health, its effect on UV may not be. In summer there is a greater probability of skin damage in New Zealand, due to the more intense UV irradiance, which can lead to skin cancer. In the winter, when UV intensities are lower than in Tokyo, there is a greater risk of insufficient vitamin D production (the action spectrum for vitamin $\mathrm{D}$ production is similar to that for erythema) (McKenzie et al., 2004).

In Tokyo, locations where the horizons are unimpeded by buildings are hard to find. Even for the measurement described here, there were significant effects. As far as the general public are concerned, the prevalence of high buildings which block the sky, and lifestyle choices, characterised by spending a larger fraction of time indoors will be important factors which further limit the personal exposure to UV radiation.

These results have important implications for our ability to accurately retrieve surface UV irradiances at polluted sites from satellites that use backscattered UV. Supplementary data characterising these boundary layer effects is probably needed.

Acknowledgements. We thank Darius Pissulla from the University of Hannover for development of analysis tools that were useful in this study. Ozone column amounts and vertical profiles of ozone and temperature were provided by Greg Bodeker from NIWA Lauder, and Birgit Hassler, from the University of Munich.

Edited by: A. Hofzumahaus

\section{References}

Badosa, J., McKenzie, R. L., Kotkamp, M., Calb’, J., González, J. A., Johnston, P. V., O'Neill, M., and Anderson, D. J.: Towards closure between measured and modelled UV under clear skies at four diverse sites, Atmos. Chem. Phys., 7, 2817-2837, 2007, http://www.atmos-chem-phys.net/7/2817/2007/.

Bais, A., Kazantzidis, A., Kazadzis, S., Balis, D. S., Zerefos, C. S., and Meleti, C.: Deriving an effective aerosol single scattering albedo from spectral surface UV irradiance measurements, Atmos. Environ., 39, 1093-1102, 2005.

Bais, A. F., Zerefos, C. S., Meleti, C., Ziomas, I. C., and Tourpali, K.: Spectral measurements of solar UVB radiation and its relations to total ozone, $\mathrm{SO}_{2}$, and clouds, J. Geophys. Res., 98, 5199-5204, 1993.

Bodeker, G. E. and McKenzie, R. L.: An algorithm for inferring surface UV irradiance including cloud effects, J. Appl. Meteorol., 35, 1860-1877, 1996.

Bodeker, G. E., Scott, J. C., Kreher, K., and McKenzie, R. L.: Global ozone trends in potential vorticity coordinates using TOMS and GOME intercompared against the Dobson network: 1978-1998, J. Geophys. Res., 106, 23 029-23 042, 2001.

Bruhl, C. and Crutzen, P. J.: On the disproportionate role of tropospheric ozone as a filter against solar UV-B radiation, Geophys. Res. Lett., 16, 703-706, 1989.

Chin, M., Chu, A., Levy, R., Remer, L., Kaufman, Y., Holben, B., Eck, T., Ginoux, P., and Gao, Q.: Aerosol distribution in the Northern Hemisphere during ACE-Asia: Results from global model, satellite observations, and Sun 
photometer measurements, J. Geophys. Res, 109, D23S90, doi:10.1029/2004JD004829, 2004.

Chubarova, N.: UV variability in Moscow according to long-term UV measurements and reconstruction model, Atmos. Chem. Phys., 8, 3025-3031, 2008, http://www.atmos-chem-phys.net/8/3025/2008/.

Hassler, B., Bodeker, G. E., and Dameris, M.: Technical Note: A new global database of trace gases and aerosols from multiple sources of high vertical resolution measurements, Atmos. Chem. Phys., 8, 5403-5421, 2008, http://www.atmos-chem-phys.net/8/5403/2008/.

Hofmann, D., Bonasoni, P., De Maziere, M., Evangelisti, F., Giovanelli, G., Goldman, A., Goutail, F., Harder, J., Jakoubek, R., Johnston, P., Kerr, J., Matthews, W. A., McElroy, T., McKenzie, R., Mount, G., Platt, U., Pommereau, J. P., Sarkissian, A., Simon, P., Solomon, S., Stutz, J., Thomas, A., Van Roosendael, M., and $\mathrm{Wu}, \mathrm{E} .:$ Intercomparison of UV/visible spectrometers for measurements of stratospheric $\mathrm{NO}_{2}$ for the Network for the Detection of Stratospheric Change, J. Geophys. Res., 100, 16765$16791,1995$.

Hönninger, G., von Friedeburg, C., and Platt, U.: Multi axis differential optical absorption spectroscopy (MAX-DOAS), Atmos. Chem. Phys., 4, 231-254, 2004,

http://www.atmos-chem-phys.net/4/231/2004/.

Jacobson, M. Z.: Isolating the causes and effects of large ultraviolet reductions in Los Angeles, J. Aerosol Sci., 29, S655-S656, 1998.

Johnston, P. V. and McKenzie, R. L.: Long-path absorption measurements of tropospheric $\mathrm{NO}_{2}$ in rural New Zealand, Geophys. Res. Lett., 11, 69-72, 1984.

Johnston, P. V. and McKenzie, R. L.: $\mathrm{NO}_{2}$ observations at $45^{\circ} \mathrm{S}$ during the decreasing phase of solar cycle 21, from 1980 to 1987 , J. Geophys. Res., 94, 3473-3486, 1989.

Kazantzidis, A., Bais, A. F., Balis, D. S., Kosmidis, E., and Zerefos, C. S.: Sensitivity of solar UV radiation to ozone and temperature profiles at Thessaloniki $\left(40.5^{\circ} \mathrm{N}, 23^{\circ} \mathrm{E}\right)$, Greece, J. Atmos. Solar-Terr. Phys., 67, 1321-1330, 2005.

Kerr, J. and Davis, J.: New methodology applied to deriving total ozone and other atmospheric variables from global irradiance spectra, Geophys. Res.-Atmos., 112, D21301, doi:10.1029/2007JD008708, 2007.

Krotkov, N. A., McClure, B., Dickerson, R. R., Carn, S. A., Li, C., Bhartia, P. K., Yang, K., Krueger, A. J., Li, Z., Levelt, P. F., Chen, H., Wang, P., and Lu, D.: Validation of $\mathrm{SO}_{2}$ retrievals from the Ozone Monitoring Instrument over NE China, J. Geophys. Res., 113, D16S40 doi:10.1029/2007JD008818, 2008.

Liley, J. B.: Global dimming, clouds and aerosols, in: UV Radiation and its Effects: an update, Royal Society of New Zealand, Wellington, New Zealand, Misc. Series, 68, 14-15, 2006.

Madronich, S. and Flocke, S.: Theoretical estimation of biologically effective UV radiation at the earth's surface, in: Solar U1traviolet Radiation. NATO, Series I: Advanced Study Institute, edited by: Zerefos, C. S. and Bais, A. F., Springer, Berlin, 2348, 1995.

Mayer, B. and Seckmeyer, G.: Retrieving ozone colums from spectral direct and global UV irradiance measurements, in: Proceedings of the XVIII Quadrennial Ozone Symposium, edited by: Bojkov, R. D. and Visconti, G., Parco Scientifico e Technologico d'Abruzzio, L'Aquila, Italy, 935-938, 1998.
McKenzie, R., Smale, D., Bodeker, G., and Claude, H.: Ozone profile differences between Europe and New Zealand: Effects on surface UV irradiance and its estimation from satellite sensors, J. Geophys. Res., 108, 4179, doi:10.1029/2002JD002770, 2003.

McKenzie, R., Smale, D., and Kotkamp, M.: Relationship between UVB and erythemally weighted radiation, Photochem. Photobiol. Sci., 3, 252-256, 2004.

McKenzie, R. L., Kotkamp, M., and Ireland, W.: Upwelling UV spectral irradiances and surface albedo measurements at Lauder, New Zealand, Geophys. Res. Lett., 23, 1757-1760, 1996.

McKenzie, R. L., Johnston, P. V., and Seckmeyer, G.: UV spectroradiometry in the network for the detection of stratospheric change (NDSC), in: Solar Ultraviolet Radiation. Modelling, Measurements and Effects, edited by: Zerefos, C. S. and Bais, A. F., Springer-Verlag, Berlin, 279-287, 1997.

McKenzie, R. L., Paulin, K. J., and Madronich, S.: Effects of snow cover on UV radiation and surface albedo: a case study, J. Geophys. Res., 103, 28 785-28 792, 1998.

McKenzie, R. L., Bodeker, G. E., Scott, G., and Slusser, J.: Geographical differences in erythemally-weighted UV measured at mid-latitude USDA sites, Photochem. Photobiol. Sci., 5, 343352, 2006.

Oltmans, S. J., Johnson, B. J., Harris, J. M., Thompson, A. M., Liu, H. Y., Chan, C. Y., Vomel, H., Fujimoto, T., Brackett, V. G., Chang, W. L., Chen, J.-P., Kim, J. H., Chan, L. Y. and Chang, H.-W.: Tropospheric ozone over the North Pacific from ozonesonde observations, J. Geophys. Res., 109, D21301, doi:10.1029/2003JD003466, 2004.

Petters, J. L., Saxena, V. K., Slusser, J. R., Wenny, B. N., and Madronich, S.: Aerosol single scattering albedo retrieved from measurements of surface UV irradiance and a radiative transfer model, J. Geophys. Res., 108, 4288, doi:10.1029/2002JD002360, 2003.

Pfister, G., McKenzie, R. L., Liley, J. B., Thomas, A., Forgan, B. W., and Long, C. N.: Cloud coverage based on all-sky imaging and its impact on surface solar irradiance, J. Appl. Meteorol., 42, 1421-1434, 2003.

Seckmeyer, G. and McKenzie, R. L.: Increased ultraviolet radiation in New Zealand $\left(45^{\circ} \mathrm{S}\right)$ relative to Germany $\left(48^{\circ} \mathrm{N}\right)$, Nature, 359, 135-137, 1992.

Shirai, T., Yokouchi, Y., Blake, D., Kita, K., Izumi, K., Koike, M., Komazaki, Y., Miyazaki, Y., Fukuda, M., and Kondo, Y.: Seasonal variations of atmospheric C-2-C-7 nonmethane hydrocarbons in Tokyo, J. Geophys. Res., 112, 24 305-24 305, 2007.

Tanskanen, A., Määttä, A., Krotkov, N., Kaurola, J., Koskela, T., Karpetchko, A., Fioletov, V., and Bernhard, G., Validation of the OMI surface UV data, in: AGU Fall Meeting, American Geophysical Union, 2005.

Wang, Y., Xin, J., Li, Z., Wang, S., Wang, P., Hao, W. M., Nordgren, B. L., Chen, H., Wang, L., and Sun, Y.: Seasonal variations in aerosol optical properties over China, Atmos. Chem. Phys. Discuss., 8, 8431-8453, 2008, http://www.atmos-chem-phys-discuss.net/8/8431/2008/.

Wuttke, S., Bernhard, G., Ehramjian, J. C., McKenzie, R., Johnston, P., O'Neill, M., and Seckmeyer, G.: New spectrometers complying with the NDSC standards, J. Ocean. Atmos. Technol., 23, 241-251, 2006. 